\title{
The Histochemical Demonstration of Adenosinetriphos- phatase Activity in Tissue Section
}

\author{
The Analysis of the Enzymatic Dephosphorylation Products \\ from Adenosine Triphosphate by the Paper \\ Chromatographic Technique
}

Heima UEMATSU and Takako KaWASUMI

Department of Anatomy Nagoya City University Medical School, Nagoya, Japan (Director: Prof. H. Uematsu)

\begin{abstract}
Introduction
The progress in the histochemical technique, including the introduction of Gomori-Takamatsu technique for alkaline phosphatase ${ }^{1-3)}$ has made capable of the histochemical demonstration of adenosinetriphosphatase (ATPase) activity ${ }^{4-9)}$ in tissue section and contributed to considerable additional information on cell structure and function.

The knowledge of the recent biological chemistry, on the other hand, has showed that the living organism contains many species of enzymes which function separately from other enzymes and as a component of the complex enzyme system or the multi-enzyme system. ${ }^{10)}$ The substrate specificity of various species of enzymes to the substrate adenosine triphosphate (ATP) is considered to be of special importance to the histochemistry of ATPase with the complexity which characterizes the difficulty of the histochemical demonstration of true ATPase activity in tissue section.

In recent years, the availability of paper chromatographic techniques offers a new and valuable approach to the isolation and analysis of the materials in minute amount in the biochemical study. The present report concerns to the enzymatic dephosphorylation products of ATP with rat kidney homogenates.
\end{abstract}

\section{Materials and Methods}

As a material were used adult albino rats fed in our laboratory. After the rat was sacrificed, the kidney tissue was removed. The experiments of the adenosine triphosphate dephosphorylation with kidney tissue homogenates of rats, 2 to $4 \mathrm{mg}$ per $0.1 \mathrm{ml}$., wet weight, were carried out at $37.5^{\circ} \mathrm{C}$ on various $\mathrm{pH}$ range $(7.0,7.2,7.4,7.5,8.1,8.6,9.0,9.4,9.5)$ in a system patterned after DuBois and Potter. ${ }^{11}$ In this system the final concentrations were as follows: sodium barbiturate, $23 \mathrm{mM}$; ATP, $6 \mathrm{mM}$; $\mathrm{Ca}^{++}, 14 \mathrm{mM}$, The ATP (disodium salt) used was purchased from the Sigma Chemical Co. and National Biochemical Co. The purity of ATP was paper chromatographically examined and the absence of spots of adenosine diphosphate (ADP) and adenosine- $5^{\prime}$-monophosphate ( $A 5^{\prime} \mathrm{MP}$ ) 
was confirmed before use. After the termination of the incubation period, 1 volume of the $50 \%$ trichloroacetic acid was added to 5 volumes of the incubating medium. The mixture of the medium and trichloroacetic acid was centrifuged at 3000 r.p.m. for 10 minutes and after this, the cation was excluded from the mixture with the use of ion-exchange resin. Thus, the products of enzymatic dephosphorylation of ATP were paper chromatographically examined by the Sekiguchi method : $\left.{ }^{12}\right) 0.02 \mathrm{ml}$. of the solution containing the decomposed products (nucleotides or phosphate-esters) were spotted on the Toyo-Roshi No. 51A and the ascending paper chromatography was carried out at $0^{\circ}-5^{\circ} \mathrm{C}$ for $70-72$ hours until the solvent front reaches the upper edge of the paper. The development reagent is as follows : isoamyl alcohol, $5 \mathrm{ml}$; isopropanol, $15 \mathrm{ml}$; lactic acid $\left(85, \sigma^{\prime}\right)$, $0.5 \mathrm{ml} ; 5 \%$ trichloroacetic acid, $10 \mathrm{ml}$. The detection of spots of the nucleotides (phosphate-esters) was generally done by ultraviolet absorption $(260 \mathrm{~m} \mu) . \mathrm{R}_{F}$ values were determined: ATP, 0.09; ADP, 0.25; A5MP, 0.37.

\section{Results and Discussion}

We found that the enzymatic dephosphorylation of ATP with the kidney tissue homogenates of rats leads to the production of ADP and A5'MP in such a short incubation period as 15 minutes, but to $\mathrm{A} 5^{\prime} \mathrm{MP}$ at the incubation period as 30 minutes, 1,2,3,4, 5 and 24 hours at various $\mathrm{pH}$ value ranging from 7.0 to 9.5 in the incubating medium of DuBois-Potter. It was proved that no trace of spots was detected on the paper chromatogram obtained, when ATP was omitted from the incubating medium as control.

In the Figure 1, the most rapid moving area (c in Fig. 1) shows the spot of $\mathrm{A5}^{\prime} \mathrm{MP}$ and next area ( $\mathrm{b}$ in Fig. 1) ADP and slowest moving area (a in Fig. 1) corresponds to the spot of ATP on the value of $R_{F}$. The spot of ADP arises from ATP owing to the enzymatic decomposition of ATP through the action of ATPase present in the kidney tissue homogenate. As indicated in the formula (1), the spot of A5'MP occurs chiefly by the function of myokinase (adenylate kinase) from ADP which primarily produced in the incubating medium by the action of ATPase and, furthermore, perhaps from ADP by the ADPase. It also seems quite likely that the spot of $A 5^{\prime} \mathrm{MP}$ would

$$
\mathrm{ADP} \stackrel{\text { Myokinase }}{\rightarrow} \mathrm{A} 5^{\prime} \mathrm{MP}+\mathrm{ATP}
$$

be probably produced from ATP by the function of the non-specific alkaline phosphatase and polyphosphatase.

It is already known that the enzymatic dephosphorylation of ATP by tissue homogenate (liver) results in the production of various nucleotides (ADP, A5'MP) (Novikoff et al., '52). ${ }^{13)}$ However, no simple and available method probably has been attempted yet on the isolation and identification of enzymatic dephosphorylation products of ATP with animal tissue homogenates although Novikoff et al. presented supporting evidences on the isolation and identification of enzymatic decomposition products of ATP with liver tissue homogenates by the slightly modified method of Hitchings and Fuller in their paper. It is found that the paper chromatographic method used here is one of the newest and the 


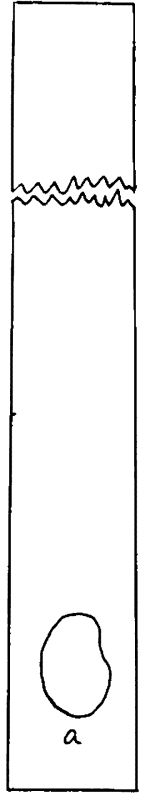

(1)

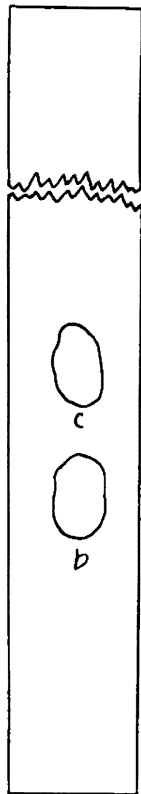

(2)

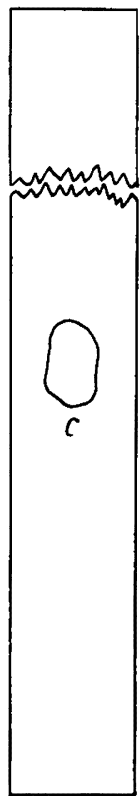

(3)

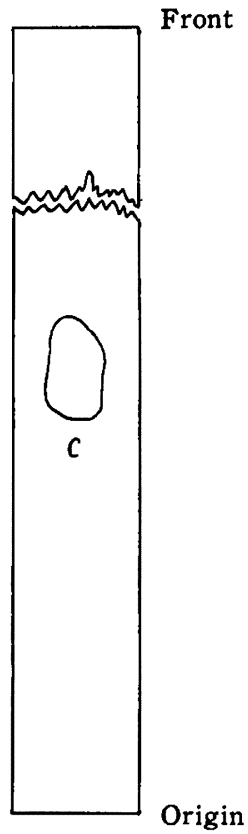

(4)

Fig. 1 The illustration of tracing of the paper chromatogram of the enzymatic dephosphorylation products of ATP with the kidney tissue homogenate of rats on the value of $\mathrm{pH} 9.5$. The paper chromatogram on the other $\mathrm{pH}$ value $(7.0,7.2,7.4,7.5,8.1,8.6,9.0,9.4)$ indicates the similar pattern to that in the case of $\mathrm{pH} 9.5$. As an incubating medium was used the medium of DuBois-Potter. The spot $b$ in (2) shows spot of ADP and spot $c$, that of $A 5^{\prime} \mathrm{MP}$ in the case of the incubation of 15 minutes; the spot $\mathrm{c}$ in (3) indicates spot of $\mathrm{A5} 5^{\prime} \mathrm{MP}$ in the case of the 30 minutes (or $1,2,3,4,5$ and 24 hours) incubation. The spot a in (1) indicates spot of ATP and the spot $c$ in (4) is that of $A 5^{\prime} \mathrm{MP}$ used as control. $\mathrm{R}_{\mathrm{F}}$ values are as follows: ATP, 0.09 ; $\mathrm{ADP}, 0.25$; $\mathrm{A} 5^{\prime} \mathrm{MP}, 0.37$.

most available methods, due to the ease with which ATP and the enzymatic decomposition products of ATP (ADP, A5'MP and so on) can be simply detected by the use of the ultraviolet absorption at the wave length of $260 \mathrm{~m} \mu$.

The present paper chromatographic result shows that the presence of spot of ADP in Fig. 1 indicates chiefly the enzymatic activity of ATPase and the spot of $A 5$ 'MP seems to be formed through the activity of ADPase, although the function of the non-specific alkaline phosphatase and polyphosphatase is speculated. The spot of A5'MP indicates especially the possibility that besides ADPase, myokinase (adenylate kinase) acts on ADP which was enzymatically decomposed from ATP by the action of ATPase in the incubating medium and as a result of this, are formed $\mathrm{A}^{\prime} \mathrm{MP}$ and ATP. ${ }^{13)}$ The result of this experiment also indicates that the enzymatic activity above stated, is recognized on every $\mathrm{pH}$ value ranging from 7.0 to 9.5 although the optimal $\mathrm{pH}$ value is not clearly demonstrated. Accordingly, it seems to be possible that the finding of enzymatic dephosphorylation products on paper chromatogram above described on various 
$\mathrm{pH}$ range of alkaline side might be the evidence of the presence of many species of enzymes which split also the substrate ATP on their proper optimum pH value.

How ATP and its derivatives are enzymatically decomposed under the action of various species of enzymes has not been so much reported until the publication of the paper of Novikoff et al. in which the over-all possibilities of the presence of various enzymes splitting ATP and its derivatives were discussed and illustrated $^{13)}$ when ATP was used as substrate in the biochemical experiments. Although the enzymatic histochemical method can demonstrate and determine generally the localization of an enzyme activity in tissue section, the enzymatic activity of true ATPase localized, however, will be still much difficult to be differentiated and identified even with the use of the appropriate inhibitors to the other enzymes localized in tissue section, due to the function of many ATP- and its derivatives-splitting enzymes present in it. Thus, the result obtained here with the paper chromatographic technique seems to be helpful and fully reliable to appreciate the result of the enzymatic dephosphorylation of ATP and histochemically to find true ATPase activity in kidney tissue section.

\section{Summary}

The experiments of the ATP dephosphorylation with rat kidney tissue homogenate 2 to $4 \mathrm{mg}$ per $0.1 \mathrm{ml}$, wet weight, were carried out at $37.5^{\circ} \mathrm{C}$ on various $\mathrm{pH}$ range $(7.0,7.2,7.4,7.5,8.1,8.6,9.0,9.4,9.5)$ in a system patterned after DuBois-Potter. It is found that the enzymatic dephosphorylation of ATP with kidney tissue homogenates leads to the production of $\mathrm{ADP}$ and $\mathrm{A} 5^{\prime} \mathrm{MP}$ in such a short incubation period as 15 minutes, but to $\mathrm{A} 5^{\prime} \mathrm{MP}$ at the incubation period as 30 minutes, $1,2,3,4,5$ and 24 hours.

Accordingly, from these experiments, it can be concluded that in such a system of incubation, dephosphorylation based upon other enzymatic function besides ATPase (probably, myokinase, ADPase, non-specific alkaline phosphatase and polyphosphatase) will perhaps occur in prolonged incubation time. Knowledge of these experiments provides a background for the understanding of the action of true ATPase to the substrate ATP on fresh-frozen section and permits a reliable analysis of histochemical demonstration of ATPase activity in tissue section.

\section{References}

1) Gomori, G.; Proc. Soc. Exper. Biol. \& Med. 42, 23, $1939 . \quad$ 2) Takamatsu, H. ; Manshu Igaku Zashi 31, 34, 1938. 3) Takamatsu, H.; Tr. Soc. Jap. 29, 1939.4 4) Glick, D. and E. E. Fischer ; Science 102, 429, $1945 . \quad 5)$ Glick, D. ; Science 103, 599, $1946 . \quad 6)$ MaengwynDavies, G. D., Friedenwald, J. S. and R. T. White ; J. Cell. \& Comp. Physiol. 39, 395, 1952. 7) Padykula, H. A. and E. Herman; J. Histochem. Cytochem. 3, 161, 1955.8 8) Padykula, H. A. and E. Herman; J. Histochem. Cytochem. 3, 170, 1955. 9) Wachstein, M. and E. Meisel ; Amer. J. Clin. Path. 27, 13, $1957 . \quad 10)$ Dixon, M. ; Multi-enzymes, Cambridge University Press, London, 1951. 11) DuBois, K. P. and V. R. Potter; J. Biol. Chem. 150, 185, 1943. 12) Yoshikawa, H. and T. Takahashi; The experimental method of phosphoric metabolism I (in Japanese) p. 119, Hirokawa Publishing Company, 1958.113 ) Novikoff, A. B., Hecht, L., Podber, E. and J. Ryan ; J. Biol. Chem., 194, 153, 1952. 